\title{
Clube de Ciências Digital Interativo
}

\author{
Rafaela Masson ${ }^{1 *}$, Ellen Francine Barbosa ${ }^{2 *}$ \\ IInstituto de Química de São Carlos e Instituto de Ciências Matemáticas e Computação da Universidade de São Paulo \\ 2Instituto de Ciências Matemáticas e Computação da Universidade de São Paulo
}

* Autoras para correspondência: masson.rafaela@gmail.com, francine@icmc.usp.br

\begin{abstract}
RESUMO
O Clube de Ciências Digital Interativo consistiu em atividades extraclasses que favorecessem a vivência da metodologia científica (nas áreas de Química, Física, Matemática, Computação e Biologia), a fim de repetir os feitos de cientistas em laboratórios. Além disso, consistiu em aproximar os alunos do âmbito universitário, fazendo com que eles conhecessem campos de pesquisa, laboratórios, e realizassem atividades dentro da universidade. $\mathrm{O}$ Clube de Ciências Digital Interativo, para suas atividades, contou com o uso de um blog na internet no qual os participantes registravam os resultados dessas atividades. Este projeto teve como público-alvo alunos do primeiro e segundo ano do Ensino Médio de instituições públicas de ensino e foi desenvolvido no escopo das atividades do Instituto de Estudos Avançados (IEA), Polo São Carlos.
\end{abstract}

Palavras-chave: Clube de Ciências; Ensino de Ciências; Espaço Não Formal.

\begin{abstract}
The Interactive Digital Science Club consisted of extra-class activities that favored the experience of scientific methodology (in the areas of Chemistry, Physics, Mathematics, Computation and Biology) in order to repeat the achievements of scientists in laboratories. In addition, it consisted of bringing the students closer to the university, making them aware of the research fields, laboratories and activities within the university. The Interactive Digital Science Club, for its activities, counted on the use of an internet blog in which the participants recorded the results of the activities carried out. This project had as target audience students of first and second year high school of public education institutions and was developed within the scope of the Instituto de Estudos Avançados (IEA), Polo São Carlos activities.
\end{abstract}

Keywords: Science Club; Science Teaching; Non-Formal Space.

\section{Introdução}

Desde que nascemos, temos contato com inúmeras situações e contextos que colaboram para formar o que somos atualmente. Nessa perspectiva, o ambiente familiar se caracteriza como o primeiro e importante fator de formação do indivíduo, mas não é o único. Existem outros espaços que contribuem para a educação das pessoas.

A educação, para alguns autores, pode ser dividida em três diferentes formas. Para Colley, Hodkinson e Malcolm (2005), essa divisão é descrita como educação formal, desenvolvida nas escolas, um espaço que garante a realização e o desenvolvimento de uma educação atribuída e garantida a todos os cidadãos; educação informal, que decorre de processos naturais e espontâneos; e educação não formal, quando existe a intenção de determinados sujeitos de criar ou buscar objetivos preestabelecidos fora da instituição escolar.

A educação não formal, para Gohm (2008), consiste em proporcionar a aprendizagem de conteúdos da escolarização formal em espaços como museus, centros de ciências, ou qualquer outro espaço em que as atividades sejam desenvolvidas com um objetivo definido.

Analisando a educação não formal, Freire destacou que:

Se estivesse claro para nós que foi aprendendo que aprendemos ser possível ensinar, teríamos entendido com facilidade a importância das experiências informais nas ruas, nas praças, no trabalho, nas salas 
de aula das escolas, nos pátios dos recreios, em que variados gestos de alunos, de pessoal administrativo, de pessoal docente se cruzam cheios de significação (FREIRE, 1997, apud GADOTTI, 2005, p. 2).

Sendo assim, atuando através da educação não formal, o Núcleo de Apoio à Pesquisa em Software Livre (NAPSoL), localizado no Instituto de Ciências Matemáticas e de Computação (ICMC) da USP São Carlos, por meio de ações como o Clube de Ciências Digital Interativo, proporcionou aos alunos de escolas públicas uma oportunidade de entrarem em contato com o "mundo científico" através de atividades experimentais relativas a temas de Química, Física, Matemática, Biologia e Computação.

Para a realização de suas atividades, o Clube de Ciências Digital Interativo contou com atividades de experimentação com abordagem investigativa, visitas a museus e centros de ciências e palestras, a fim de que os clubistas tivessem contato com pesquisas desenvolvidas dentro da universidade e, para finalizar, a realização de uma mostra de trabalhos que foi apresentada dentro da universidade e avaliada por um grupo de estudantes e pesquisadores convidados. Essas atividades promoveram a interação dos alunos de escolas públicas com a Universidade e com ambientes de estudos e pesquisa com os quais até então não haviam tido contato.

O Clube de Ciências Digital Interativo se diferenciou de outros clubes de ciências por utilizar um $b l o g$, dentro do Portal Ciência $W e b^{1}$, no qual os próprios participantes registravam, a cada atividade cumprida, os resultados obtidos e também suas impressões sobre as palestras e visitas realizadas. Nesse espaço, também estão arquivados registros em fotos e vídeos de todas as atividades, aos quais qualquer pessoa, independentemente da participação no Clube de Ciências, poderá ter acesso, a fim de estender o projeto para o público que não teve envolvimento direto com ele.

\section{Desenvolvimento}

Para a seleção dos alunos que fariam parte do Clube de Ciências Digital Interativo, foram realizadas visitas em várias instituições escolares e o convite foi feito preferencialmente para alunos do primeiro e segundo ano do Ensino Médio. A partir do interesse dos alunos, eles preencheram uma ficha de inscrição com seus dados e duas questões relacionadas com seu interesse em ciências. Foram as respostas dessas questões o ponto-chave para a seleção dos alunos participantes do Clube de Ciências.

O conteúdo abordado durante as atividades foi dividido em cinco módulos: Informática e Softwares Livres, Química, Matemática, Física e Biologia. Cada módulo incluía a realização de experimentos pelos participantes, visitas a museus ou centros de ciências e palestras com pesquisadores.

Os experimentos foram feitos pelos alunos, em sua maioria, de maneira investigativa; ou seja, após todos os conceitos necessários e dados serem oferecidos, os alunos propuseram desde o procedimento até a realização do experimento. Esta foi uma metodologia aplicada para que os alunos se comportassem como verdadeiros cientistas. No ensino por investigação,

[...] os alunos são colocados em situação de realizar pequenas pesquisas, combinando simultaneamente conteúdos conceituais, procedimentais e atitudinais (POZO, 1998). Essa abordagem também possibilita que o aluno desenvolva (exercite ou coloque em ação) as três categorias de conteúdos procedimentais (PRO, 1998): habilidades de investigar, manipular e comunicar (FERREIRA, HARTWIG \& OLIVEIRA, 2010).

As palestras consistiram em apresentações de pesquisadores, tanto professores quanto alunos, que mostraram aos participantes do clube suas pesquisas, a relação e o retorno que elas oferecem à sociedade. Foram realizadas seis palestras durante o ano.

Também como metodologia, durante $\mathrm{O}$ primeiro módulo, sobre informática e softwares livres, foram introduzidos conceitos sobre softwares livres e apresentados objetos de aprendizagem e ambientes de ensino que pudessem ser adaptados ao ensino 
de ciências. De acordo com a Free Software Foundation, um software livre consiste em:

[...] qualquer programa de computador que pode ser usado, copiado, estudado, modificado e redistribuído com algumas restrições. A liberdade de tais diretrizes é central ao conceito, o qual se opõe ao conceito de software proprietário, mas não ao software que é vendido almejando lucro (software comercial). A maneira usual de distribuição de software livre é anexar a este uma licença de software livre, e tornar o código fonte do programa disponível (BRASIL, s. d.).

Para a conclusão do Clube de Ciências, os alunos desenvolveram uma mostra de trabalhos, para a qual foram divididos em seis grupos e apresentaram, em forma de pôster e com experimentos, assuntos relacionados com ciências. Eles puderam apresentar algo que compreenderam durante o desenvolvimento do Clube ou tinham a liberdade de trazer algo externo para desenvolver. Os trabalhos foram expostos no saguão da Biblioteca Achille
Bassi, no Instituto de Ciências Matemáticas e de Computação da USP São Carlos, podendo ser visitados por alunos e docentes (Figura 1). Além disso, eles foram avaliados por cinco convidados, e o melhor trabalho recebeu um prêmio motivacional.

\section{Descrição das Atividades Desenvolvidas}

- Atividades propostas para fevereiro e março:

- Atividade 1: Planejamento das atividades experimentais desenvolvidas no Clube de Ciências Digital Interativo, por meio da realização de uma pesquisa e de escolha dos temas de cada atividade a ser feita no Clube;

- Atividade 2: Escolha dos palestrantes, realização do convite a eles e definição dos temas, procurando, neste momento, propor que sejam mostradas aos alunos atividades desenvolvidas na Universidade;

- Atividade 3: Na primeira quinzena de março, ocorre a divulgação do Clube de Ciências Digital Interativo nas escolas públicas e se faz um cadastro dos alunos interessados em participar do projeto;

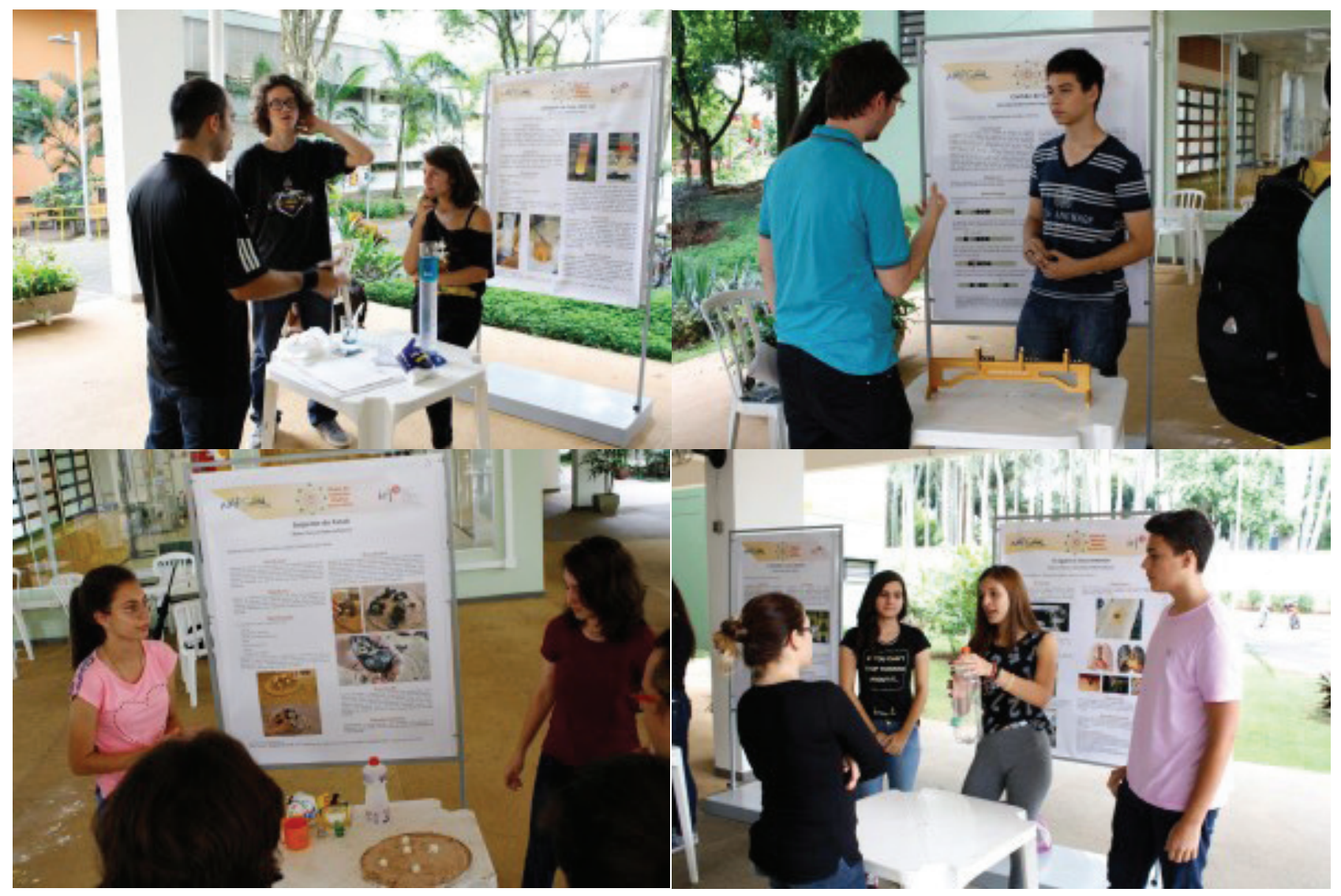

Figura 1 - Mostra de trabalhos para finalização do projeto. 
- Atividade 4: Na segunda quinzena de março, realiza-se a seleção dos alunos que participarão do Clube de Ciências, assim como a divulgação e a matrícula dos participantes.

- Atividades propostas para abril:

- 09/04: Apresentação do Clube de Ciências Digital Interativo;

- 16/04: Oficina sobre Wordpress com o aluno do ICMC Daniel Araújo;

- 23/04: Palestra a respeito do tema "Jogos e Robótica", ministrada pelo Prof. Dr. Fernando Osório (docente do ICMC) e por Julio Trasferetti Nicolucci (aluno do FoG).

- 30/04: Palestra sobre o tema "A Importância e a Aplicação dos Softwares Livres", ministrada pelo Prof. Dr. Francisco José Monaco (docente do ICMC), e palestra acerca do tema "Conteúdos Abertos", ministrada pela Prof ${ }^{a}$ Dra $^{\text {a }}$ Ellen Francine Barbosa.

- Atividades propostas para maio:

- 07/05: Torre de Líquidos - experimento investigativo sobre densidade das substâncias (Figura 2);

- 14/05: Visita ao Serviço Autônomo de Água e Esgoto (Saae) de São Carlos com o objetivo de se mostrar de que forma a Química está presente no tratamento de água;

- 21/05: Análise da quantidade de álcool em uma amostra de gasolina;

- 28/05: Palestra da Prof ${ }^{a}$ Yvonne Primerano Mascarenhas - "A Química e a Arte".

- Atividades propostas para junho:

- 04/06: Feriado (Não houve atividade);

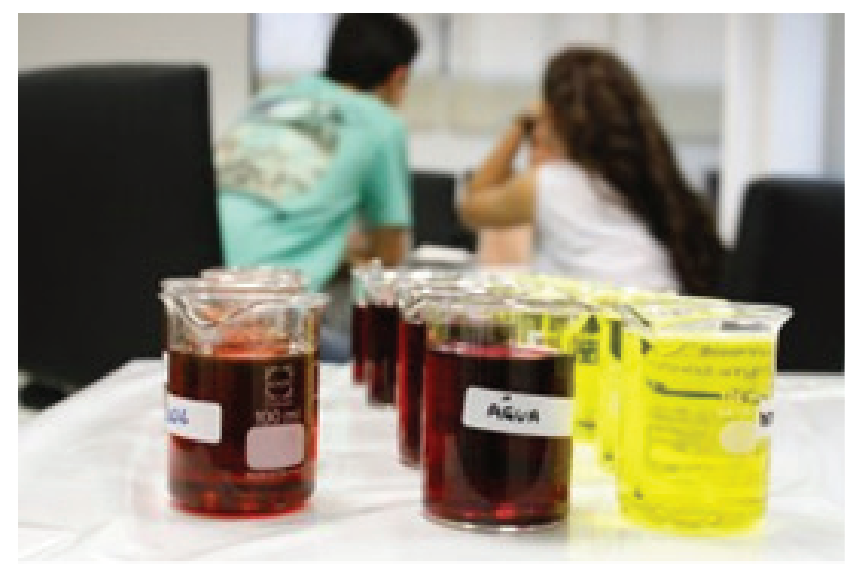

Figura 2 - Experimento "Torre de Líquidos".
- 11/06: Palestra sobre vulcanismo e experimento, "Pasta de Dente de Elefante" (Figura 3);

- 18/06: Visita guiada ao Centro de Divulgação Científica e Cultural (CDCG) da USP São Carlos;

- 25/06: Visita ao Catavento Cultural e ao Museu da Língua Portuguesa em São Paulo.

- Atividades propostas para agosto:

- 06/08: Truques de mágica baseados em conceitos de matemática - extraídos do livro Mágicas, Matemática e Outros Mistérios;

- 13/08: Confecção de origamis para explicar conceitos de Geometria (Figura 4);

- 20/08: Oficina de confecção de figuras geométricas em 3D utilizando canudos de plástico;

- 27/08: Palestra sobre "Robótica Móvel" com a Prof ${ }^{a}$ Dr $^{a}$ Roseli Aparecida Romero.

- Atividades propostas para setembro:

- 03/09: Construção de uma câmara escura;

- 10/09: Visita à Sala do Conhecimento (IFSG-USP), tendo em vista apresentar outros experimentos sobre Física;

- 17/09: Construção de uma lupa de garrafa PET;

- 27/08: Palestra sobre "Relógios Atômicos" com o Prof. Dr. Daniel Varela Magalhães, realizada no Ciclo de Palestras "Ciência e Riqueza Social".

- Atividades propostas para outubro:

- 01/10: Palestra com o Prof. Sérgio Ricardo Muniz: "A História da USP e o IFSC";

- 08/10: Visita ao observatório da USP;

- 15/10: Experimento: extração do DNA de algumas frutas (Figura 5);

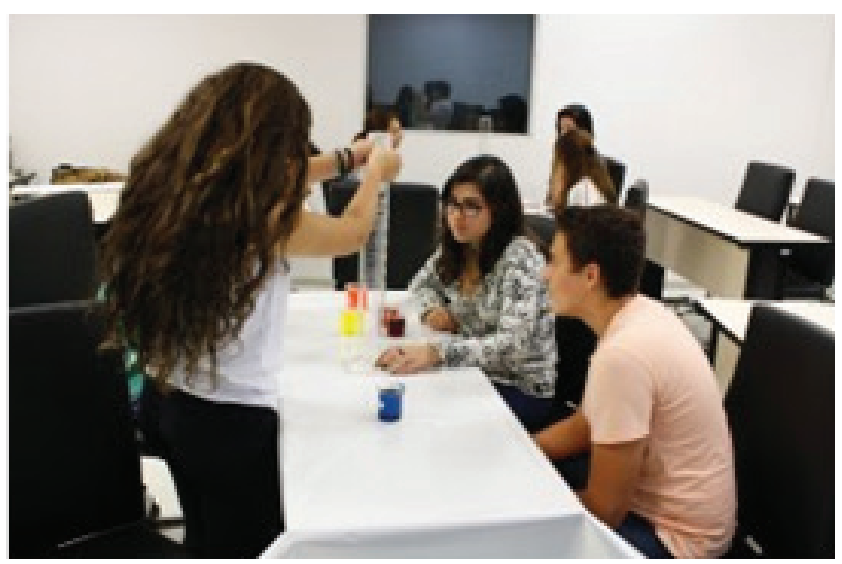




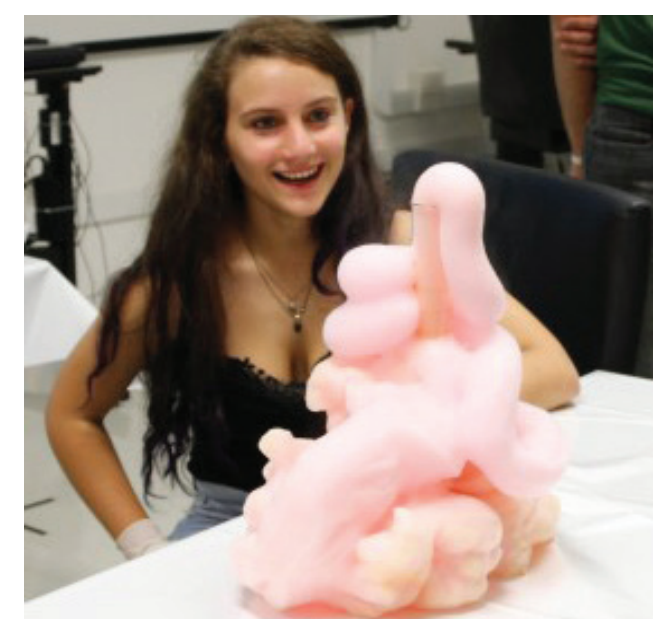

Figura 3 - Experimento "Pasta de Dente de Elefante"
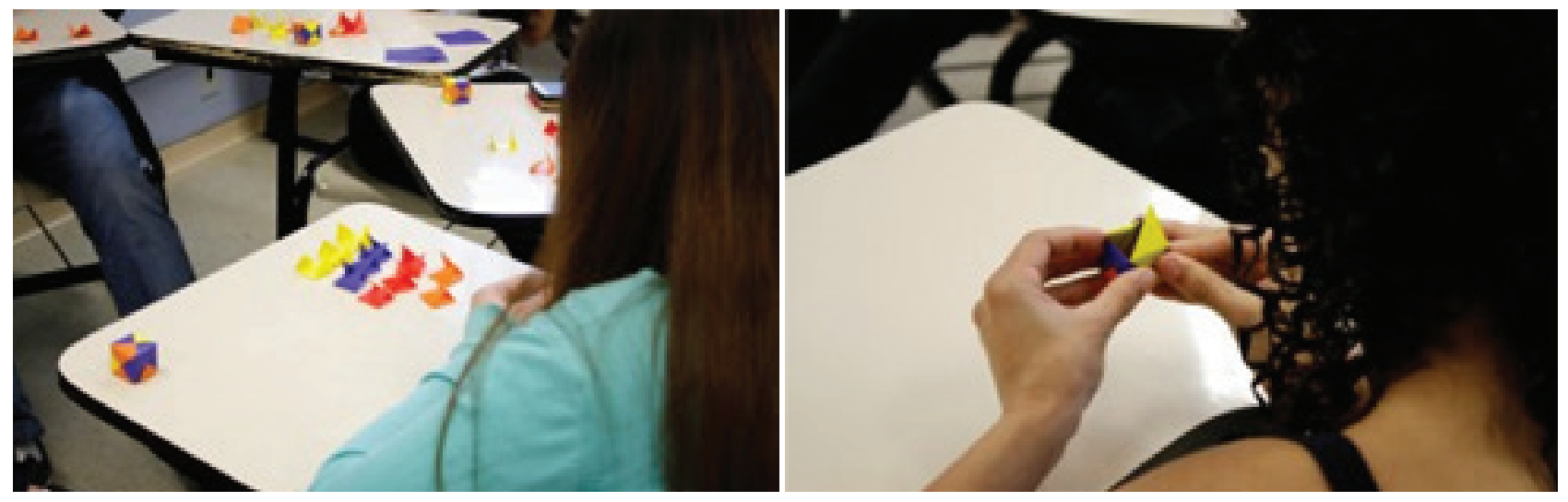

Figura 4 - Confecção de origamis.
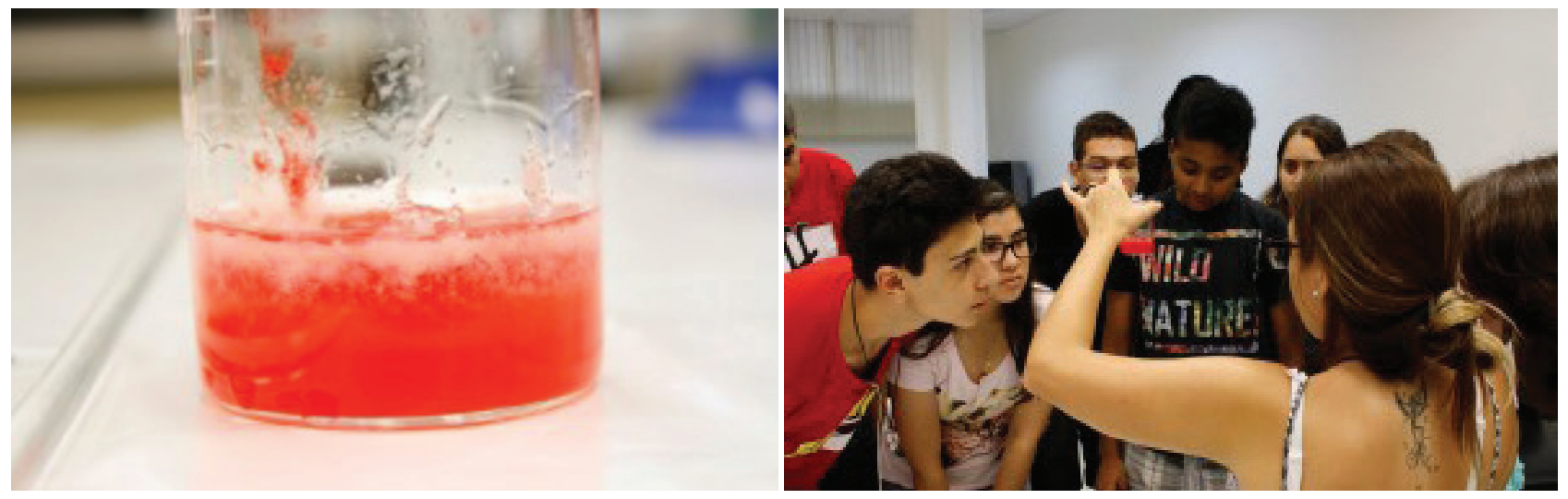

Figura 5 - Experimento "extração do DNA de algumas frutas".

- 22/10: Palestra com o doutorando Vitor Hugo Serrão: "O Que É Ciência e Biologia Molecular Estrutural";

- 29/10: Visita à Fazenda Santa Maria.

- Atividades propostas para novembro:

- 05/11: Desenvolvimento dos trabalhos para a mostra;

- 12/11: Desenvolvimento dos trabalhos para a mostra;
- 19/11: Desenvolvimento dos trabalhos para a mostra;

- 26/11: Apresentação da mostra de trabalhos (Figura 6).

\section{Conclusão}

De acordo com o que foi observado durante as atividades do Clube de Ciências e por meio do questionário avaliativo preenchido pelos alunos, 


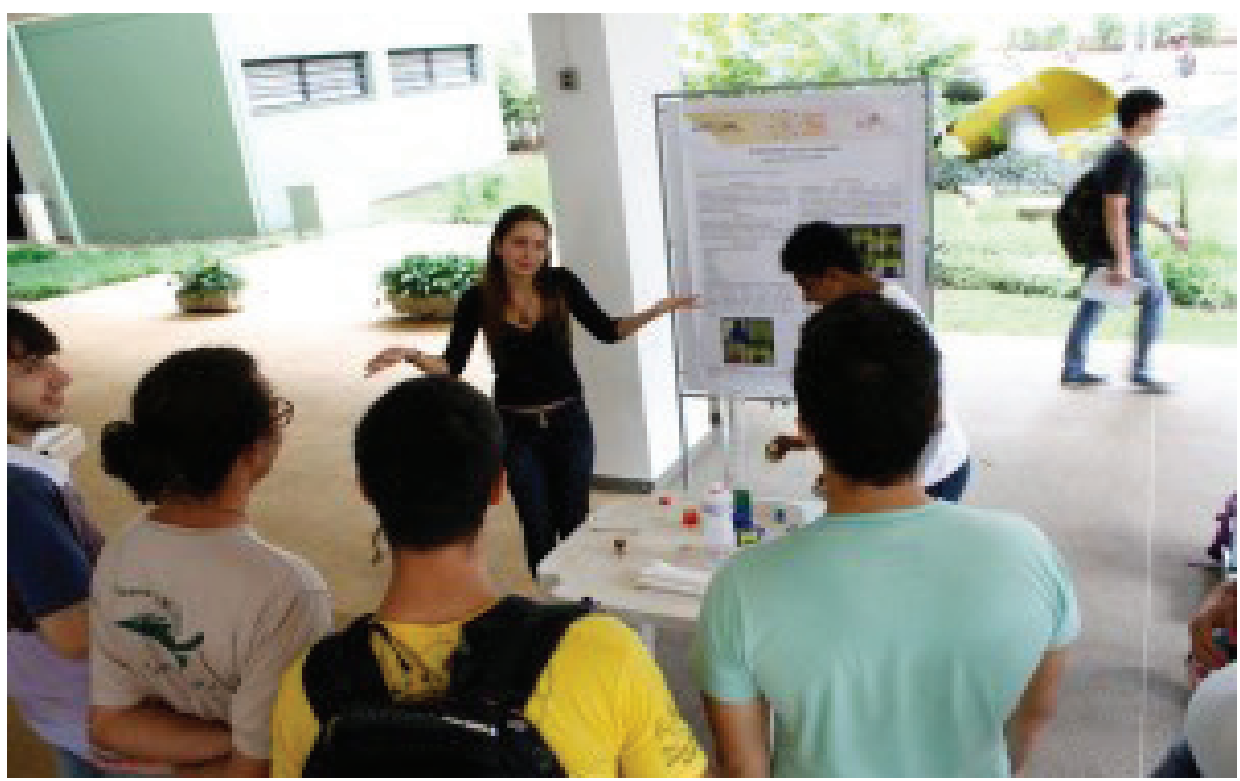

Figura 6 - Apresentação da Mostra de Trabalhos

percebe-se a eficiência da iniciativa. Com a proposta de atividades práticas, palestras e passeios, conseguiu-se maior participação dos alunos e, por consequência, efetivo interesse e aprendizado.

Ao mesmo tempo, o Clube mostrou-se uma ótima oportunidade para aproximar alunos do Ensino Médio e da universidade e fazer com que eles vislumbrassem a possibilidade de serem futuros graduandos.

Como aprendizado pessoal para as autoras do presente relato, o projeto foi de grande valia, pois permitiu levar adiante e aprofundar as atividades realizadas, fazendo com que o ensino em sala de aula também ganhasse em efetividade, apresentando-se de modo diferenciado.

Por fim, convém assinalar que o Clube teve um grande diferencial em termos de abrangência e participação, pois mesmo os alunos que não puderam tomar parte, presencialmente, das atividades promovidas pelo projeto acompanharam todas as atividades através do blog do Clube de Ciências Digital Interativo.

\section{Comentários e Sugestões Finais dos "Clubistas"}

O Clube de Ciências foi uma experiência única na minha vida, abrindo minha mente para como funciona cada área da ciência e como funciona uma universidade. Eu diria que foi uma experiência essencial para meu futuro. Apesar de estarmos há quase um ano fazendo o Clube, gostaria que houvesse outro. Mesmo que eu não participasse, acho que seria muito importante na formação de outras pessoas. (Aluno 1)

Eu gostei muito do Clube de Ciências, para mim é um projeto muito importante para nós estudantes do Ensino Médio, para nossa formação acadêmica e social, permitindo-nos frequentar a universidade, ser parte de um grupo. Outra coisa que gostei muito foram as palestras; foi bom poder entrar em contato com alunos e professores da USP. Ah, o blog para mim foi o diferencial do Clube; acho importante compartilhar nossas experiências. (Aluno 2)

Acho o Clube muito legal na parte educacional, até importante; é merecido outro clube, pois é descontraído, divertido. (Aluno 3)

Bom, o Clube de Ciências foi uma experiência que repetiria milhares de outras vezes, pois além de nos divertirmos estávamos aprendendo. E também tirei dúvidas sobre composições de alguns elementos químicos. Entre outros. E portanto o Clube deveria existir sempre. (Aluno 4)

O Clube foi um projeto legal, principalmente pra mim que não gostava de Exatas e Biológicas. Consegui aprender de maneira fácil as matérias em que eu 
tinha mais dificuldade. A verba do projeto poderia ser maior, já que é muito bom e atividades como passeios e viagens cativam muito os alunos. (Aluno 5)

Em minha opinião o Clube deveria acontecer de novo, pois auxilia em muitas coisas todos os alunos. (Aluno 6)

Adorei participar desse grupo, foi uma ótima experiência, gostaria que ocorresse novamente. (Aluno 7)

\section{Nota}

1 Disponível em: <http://www.cienciaweb.org.br/clube-de-ciencias/>. Acessado em 15 maio 2017.

\section{Referências Bibliográficas}

COLLEY, H.; HODKINSON, P. \& MALCOLM, J. "Non-Formal Learning: Mapping the Conceptual Terrain. A Consultation Report". Leeds: University of Leeds Lifelong Learning Institute, 2002. Disponível em $<$ http://www.infed.org/archives/e-texts/colley_informal_ learning.htm >. Acessado em 9 dez. 2014.

FERREIRA, L. H.; HARTWIG, D. R. \& OLIVEIRA, R. C. de. "Ensino Experimental de Química: Uma
Abordagem Investigativa Contextualizada". Química Nova na Escola, vol. 32, n. 2, maio 2010. Disponível em: $<$ http://qnesc.sbq.org.br/online/qnesc32_2/08-PE-5207. pd† $>$. Acessado em 8 nov. 2014.

GADOTTI, M. "A Questão da Educação Formal/Não Formal". Droit à L'Éducation: Solution à Tous les Problemes ou Probleme sans Solution? Institut International des Droits de L'Enfant, Sion, 2005. Disponível em: <http://pt.scribd.com/ doc/53944682/GADOTTI $\gg$. Acessado em 9 dez. 2014.

GOHN, M. G. "Educação Não Formal na Pedagogia Social". I Congresso Internacional de Pedagogia Social, 1, 2006, Proceedings Online... Faculdade de Educação, Universidade de São Paulo. Disponível em: বhttp:// www.proceedings.scielo.br/scielo.php?pid=MSC0000000092006000100034\&script=sci_arttext $>$. Acessado em 9 dez. 2014.

OLIVEIRA, R. de; PINTO, J. M. de O. \& OAIGEN, E. R. "Clubes de Ciências: Ferramenta Educacional para a Construção de Caminhos para a Iniciação à Educação Científica". IX Anped Sul, Seminário de Pesquisa em Educacão da Região Sul, Universidade de Caxias do Sul, Caxias do Sul, Rio Grande do Sul, 2012. Disponível em: বhttp://www. ucs.br/etc/conferencias/index.php/anpedsul/9anpedsul/paper/viewFile/2674/631>. Acessado em 4 out. 2014.

BRASIL. "Software Livre no Governo do Brasil". S. 1.: s.n., s.d. Disponível em: $<$ http://www.softwarelivre.gov. $\mathrm{br} /$ tire-suas-duvidas/o-que-e-software-livre $>$. Acessado em 8 nov. 2014.

Publicado em 30/06/2017. 